\title{
Correlates of Adolescent Reports of Sexual Assault: Findings From the National Survey of Adolescents
}

\author{
Rochelle F. Hanson \\ Medical University of South Carolina \\ Lisha W. Kievit \\ College of Charleston, South Carolina \\ Benjamin E. Saunders \\ Daniel W. Smith \\ Dean G. Kilpatrick \\ Heidi S. Resnick \\ Kenneth J. Ruggiero \\ Medical University of South Carolina
}

This study examines how key demographic variables and specific child sexual assault (CSA) incident characteristics were related to whether adolescents reported that they had told anyone about an alleged sexual assault. The study also investigates whether there were differences in the correlates of CSA disclosure as a function of gender and race/ethnicity. A national household probability sample of 4,023 adolescents was interviewed by telephone about childhood experiences, including CSA history. Significant gender and racial/ethnic differences were obtained in rates of CSA disclosure: Sexually abused boys and African American youth were less likely to report telling anyone they had been sexually abused. Separate regression models examining correlates of CSA disclosure yielded differences as a function of gender andrace/ethnicity.

Keywords: sexual assault; adolescents; abuse disclosure; child sexual abuse

D espite the many studies documenting the adverse initial and long-term effects of child sexual abuse (CSA) (e.g., Beitchman et al., 1992; Finkelhor, 1994;

CHILD MALTREATMENT, Vol. 8, No. 4, November 2003 261-272 DOI: $10.1177 / 1077559503257087$

(C) 2003 Sage Publications
Fleming, Mullen, Sibthorpe, \& Bammer, 1999; Polusny \& Follette, 1995; Saunders, Kilpatrick, Hanson, Resnick, \& Walker, 1999), research suggests that only a small number of children who are sexually abused will eventually tell an adult about the abuse. Factors such as the fear of not being believed, the fear of being punished, and feelings of shame have been proposed as reasons for a child's decision not to tell about sexual abuse incidents (Roesler \& Wind, 1994; Sauzier, 1989). Studies have also indicated that disclosure of abuse may increase the likelihood of psychological problems, such as anxiety and difficulties in coping (e.g., Elliot \& Briere, 1994; Nagel, Putnam, Noll, \& Trickett, 1997). Thus, studies seem to suggest that telling about the abuse, at least during childhood, may be neither easy nor beneficial for the children who disclose.

Authors' Note: This research was supported by Grant No. 93-IJ-CX0023 from the National Institute of Justice, Dean G. Kilpatrick and Benjamin E. Saunders, principal investigators. Points of view or opinions expressed in this article do not necessarily represent the official position or policies of the U.S. Department of Justice. Correspondence concerning this article should be addressed to Rochelle F. Hanson, Ph.D., National Crime Victims Research and Treatment Center, Medical University of South Carolina, P.O. Box 250852, Charleston, SC 29425; e-mail: hansonrf@musc.edu. 
If it is the case that a childhood report of CSA tends to be recalled by victims as a negative and unhelpful experience, are there reasons to believe that a child should tell someone? Telling someone is the primary mechanism by which child victims are identified, since typically no one else is witness to the abuse, and offenders rarely come forward on their own. To stop ongoing abuse, the abuse must first be discovered. Although retrospective accounts of CSA survivors, as well as clinical samples, suggest that adults do not always take swift action following a child's disclosure of abuse, it is unclear whether larger, prospective research may reveal differing results. In view of the substantial evidence from the research literature that supports the negative long-term effects of CSA (Beitchman et al., 1992; Fleming et al., 1999; Lipovsky \& Kilpatrick, 1992; Polusny \& Follette, 1995), it would seem essential to be able to identify child victims as early as possible to stop the abuse, to prevent future abuse, and to initiate interventions.

Furthermore, although the relationship between CSA disclosure and mental health consequences is clearly an important area of research, we remain largely unaware of the factors that contribute to a child's decision to tell someone they have experienced CSA. Telling someone about sexual abuse, and by extension, attempts to determine what increases the likelihood of telling, is particularly important in the legal arena. In order to press charges against a perpetrator and prevent additional victimizations, identification of the perpetrator must first be made. By understanding which factors contribute to a child's likelihood of telling, we increase the possibility of being able to identify and prosecute CSA perpetrators (Paine \& Hansen, 2002).

\section{Correlates of CSA Disclosures}

Despite the importance of being able to predict disclosure of CSA, only a few studies have provided information on the topic of when, how, why, and to whom children tell about their CSA experiences (Lamb \& Edgar-Smith, 1994; Paine \& Hansen, 2002; Roesler, 1994; Sauzier, 1989; Smith et al., 2000). Furthermore, the findings related to the prediction of who discloses CSA are difficult to interpret given the large methodological differences (e.g., sample size, population used, differences in definitions of CSA and disclosure) between studies. Nonetheless, several factors have gained support as important in predicting who tells someone about their CSA. First, severity of abuse has been documented by several studies as a correlate of CSA disclosure. The direction of this relationship, however, is less clear. Several studies have found that the more severe the abuse, the less likely a child will tell. For example, Wyatt \& Newcomb (1990) found that severity of CSA (as measured by type of incident and use of physical force) was related to a reduced likelihood of telling. Sauzier (1989) found that severity of abuse was related to the immediacy of the report, such that minor forms of abuse (e.g. exhibitionism, attempted contact) were most likely to result in the child's telling someone sooner. In contrast, Smith et al. (2000) did not find a relationship between severity of the assault (as measured by perception of life threat, receipt of physical injury, or presence of a weapon) and time of disclosure. More specifically, severity of the abuse did not differentiate between women who reported telling someone within 1 month of the abuse, compared to women who delayed their disclosure (defined in the study as a disclosure that occurred more than 1 month after the abuse). However, in the Smith et al. (2000) study, women who delayed disclosure were more likely to have experienced a series of rapes, another measure of assault severity, compared to women who reported an immediate disclosure. In addition, the strategies used by perpetrators to engender the child's cooperation have provided mixed results with regard to a child's report of CSA. For example, Sauzier (1989) found that the use of aggressive tactics by the perpetrator resulted in either immediate report by the child or no report at any point in time.

Another factor related to telling about CSA is age of the victim. Younger age at the time of the abuse has been related to a reduced likelihood of the child's telling someone about their assault (Nagel et al., 1997; Smith et al., 2000; Sorenson \& Snow, 1991). It has been hypothesized that developmental factors may contribute to the lack of purposeful telling in young children who are not cognitively mature and who may not understand that sexual abuse is wrong or may not be able to communicate this through verbal means.

Degree of acquaintanceship with the perpetrator (Arata, 1998; Wyatt \& Newcomb, 1990) is another factor that appears important to the process of telling. Children who are acquainted with and have a closer relationship to the perpetrator have been shown as less likely to tell someone than are children who are assaulted by someone whom they do not know (Smith et al., 2000; Wyatt \& Newcomb, 1990). For example, in the Smith et al. (2000) study, women who delayed telling someone about their childhood rape were twice as likely to have been related to the perpetrator compared with women who told someone within 1 month. In contrast, women who disclosed immediately (i.e., within 1 month) were over four times more likely to 
have been raped by a stranger than those who delayed their disclosure.

In addition to the factors discussed above, another variable that may be correlated with CSA reporting by the child is the victim's use of substances (alcohol/ drugs). Investigations using adult samples have found that use of substances at the time of the assault is linked to the victim's being blamed for the assault (Goodchilds \& Zellman, 1984; Richardson \& Campbell, 1982). Hence, one possibility is that victims might feel less able to tell about CSA in situations where blame is anticipated. Substance use by the victim might also then prove to be a correlate of CSA reports among older children and adolescents.

\section{Race/Ethnicity}

With regard to race/ethnicity, authors (McNair \& Neville, 1996; Wyatt, 1992) have suggested that, for historical reasons, African American women are more likely to be seen by society as highly sexualized, and thereby having contributed to their own sexual assault. Additionally, some authors have suggested that the legal system in the United States has responded less seriously to sexual assaults on African American women than to assaults on European American women (Wyatt, 1992). Consequently, African American girls may be less likely to disclose to authorities than European American girls for fear of not being believed or taken seriously. Wyatt (1992) found that African American women were significantly less likely than European American women to tell someone about a sexual assault experience. In contrast, Smith et al. (2000) failed to find any differences in disclosure patterns as a function of race/ethnicity, meaning that any potential relationships among race/ethnicity and telling about sexual abuse remain equivocal at the present time.

\section{Gender}

As reviewed by Paine and Hansen (2002), studies have yielded equivocal findings regarding gender and CSA disclosure. Although some studies have failed to find a relationship between gender and abuse disclosure (e.g., Bybee \& Mowbray, 1993; DiPietro, Runyan, \& Fredrickson, 1997; Sauzier, 1989), others have indicated that boys are less likely to disclose than are girls (i.e., Bolton, Morris, \& MacEachron, 1989; Finkelhor, Hotaling, Lewis, \& Smith, 1990; Lamb \& Edgar-Smith, 1994). In particular, research has suggested that adolescent boys are the least likely to tell someone about their sexual abuse (e.g., Hecht \& Hansen, 1999; Lamb \& EdgarSmith, 1994; Watkins \& Bentovim, 1992) Other research has suggested different characteristics of the
CSA experience (e.g., age of onset, intra- vs. extrafamilial victimization) for male and for female victims that might also lead to differences in likelihood of disclosure (Faller, 1989; Mey, 1988). Finally, the prevalence rates of sexual abuse have been documented as lower for boys than for girls (Friedrich, 1998; Holmes \& Slap, 1998; Swenson \& Hanson, 1998). This might signal a true difference in the prevalence of sexual abuse in boys, or it might indicate that boys are equally as likely to be sexually abused but less likely to tell someone.

Despite reasons to suspect that there may be different patterns or correlates of disclosure in boys and girls, these issues have yet to be adequately addressed, particularly with a nationally representative sample of youth. If there are, indeed, gender differences that affect telling someone, such information would be vital to identify victims of CSA, as well as to prevent revictimization.

\section{Research Questions}

The present sample is unique in being a nationally representative, random sampling of adolescents. The purpose of the current study was twofold. The primary purpose was to identify how key demographic variables and specific CSA incident characteristics were related to whether adolescents told someone about their alleged assaults. Based on a review of the literature, the following variables were hypothesized to be associated with a reduced likelihood of disclosure: (a) more severe sexual assault (i.e., as indicated by perceived life threat, penetration assault, a series of assaults, and physical injury), (b) a close relationship with the perpetrator, (c) victims' reported use of substances during their assault, (d) a younger age at the time of the assault, (e) being a male victim, and (f) being African American.

A secondary purpose of the study was to investigate whether there might be differences in the correlates of CSA disclosure for boys and girls and for adolescents of different racial/ethnic groups. This was an important next step in the investigation of who discloses CSA given differential rates of reporting between male and female victims and between African American and European American adolescents that have been documented in the literature. Additionally, there is some suggestion that the context in which CSA occurs differs for boys as compared to girls and for adolescents of different racial/ethnic backgrounds. To investigate the moderating effects of gender and race/ethnicity, regression analyses were conducted that included interaction terms (i.e., gender and the CSA incident characteristics; race/ethnicity and the CSA incident characteristics). Due to the 
exploratory nature of these analyses, no specific hypotheses are offered. However, the present sample offered an excellent opportunity for examination of these issues.

\section{METHOD}

\section{Participants}

The National Survey of Adolescents was a probability sample of 4,023 adolescents residing in households accessible by telephone in the United States. Of the total sample, 3,161 adolescents were a national probability household sample, and 862 were an oversample of adolescents living in central city areas. Participants in the study ranged in age from 12 to 17 , resided with a parent or guardian, and spoke either English or Spanish. The full sample was weighted to conform to the 1995 census estimates for American adolescents on age, race, and gender. (Please refer to Kilpatrick et al., 2000 , for a detailed explanation of the sampling procedure and full sample characteristics). As the survey was conducted by telephone, all participants had to be reached by telephone. Exclusion criteria included those adolescents residing in institutional settings with central switchboards, emancipated adolescents not living with a parent or guardian, those whose parents did not give permission for their child to participate, and those who did not speak English or Spanish.

In each household, a parent or guardian was interviewed prior to the adolescent interview to inform the parent about the study and to obtain consent. From among the 5,367 households eligible to participate, 4,836 parents completed interviews $(90.1 \%$ of eligible households) and 4,236 parents gave permission for their adolescent to be interviewed $(78.9 \%$ of eligible households; $87.6 \%$ of cases with completed parent interviews). In sum, 4,023 adolescents $(75.0 \%$ of those eligible) completed interviews.

With regard to demographic characteristics, the full weighted sample consisted of slightly more boys $(n=2,065,51.3 \%)$ than girls $(n=1,958,48.7 \%)$, was largely White and non-Hispanic $(n=2,825 ; 70.2 \%)$, and was evenly distributed across age groups. Adolescents ranged in age from 12 to 17 , with each age cohort accounting for about $16 \%$ to $17 \%$ of the total sample.

\section{Sampling Procedure}

Schulman, Ronca, and Bucuvalas, Inc., a New York-based survey research firm, conducted sample selection and interviewing. To construct the initial probability sample, a multistage, stratified, area prob- ability, random-digit dialing, six-stage sampling procedure was utilized. Details of these procedures are available from Kilpatrick et al. (2000).

\section{Procedure}

After determining that the household contained one or more eligible adolescents, the interviewer first spoke with the parent or guardian to inform him or her about the study and to obtain consent for the adolescent to participate. Whenever possible, the adolescent interview was conducted immediately after the adult interview. Two steps were taken to ensure that adolescents had a reasonable degree of privacy while responding to questions so that they could answer as openly and honestly as possible. First, the interviewer directly asked if the adolescent was in a situation where privacy was assured and he or she could respond in an open fashion. Second, the interview was designed primarily with closed-ended questions (i.e., a yes/no or a number) so that if others were listening they would hear no information that might endanger or have negative consequences for the adolescent. A previously established protocol ("Child in Danger" protocol) was also used to address any instances in which an adolescent was to become distressed during the interview (Kilpatrick et al., 2000). Specifically, the protocol involves several steps. First, interviewers are trained to identify any respondents who appear to be experiencing distress during the interview. Second, adolescents are asked if they would like to talk with one of the investigators on the project, all of whom are licensed mental health professionals with considerable experience dealing with victims of crime and other traumatic events. Third, individuals who are very distressed and/or whom the interviewers are concerned about will be told that a member of the project team will contact them to assess their current condition. Fourth, in such cases, a member of the project team will contact the respondent, ascertain their current condition, determine if they need clinical intervention, and arrange an appropriate mental health referral if they need it.

All adolescents received a certificate of participation in the "National Survey of Adolescents" and a check for five dollars.

\section{Measures}

A highly structured telephone interview and specially trained interviewers were used to gather information about a number of different topics including demographic characteristics, family history of substance abuse, victimization history (sexual and physical assault), and mental health outcomes. Only those 
sections of the interview relevant to this study are discussed below. A copy of all interview questions can be obtained from the first author.

Contact childhood sexual assault. Contact sexual assault was defined as episodes that involved forced vaginal or anal penetration by an object, finger, or penis; episodes of forced oral sex; episodes in which another person touched the respondents' breasts or genitalia against their will; or episodes in which respondents were forced to touch another's genitalia. Respondents who reported that they had experienced any of these incidents were classified as victims of CSA.

Specific steps were taken to increase the likelihood of accurate reporting when assessing experiences of sexual assault. First, an introductory paragraph was presented to participants to orient them toward the range and nature of events being assessed. Specifically, prior to administering the sexual assault questions, participants were told:

\begin{abstract}
Sometimes a person may do sexual things to a young person that the young person doesn't want. These unwanted sexual things can happen to boys as well as girls and to young men as well as young women. People who try to do unwanted sexual things to young people are not always strangers but can be someone you know well like a neighbor, teacher, coach, counselor, boss, baby-sitter, minister or priest. They can even be a family member. People who try to make young people do unwanted sexual things aren't always men or boys-they can also be women or girls. I am talking about any experiences you've had where someone tried to make you do something sexual you didn't want to do, no matter who did it, how long ago it happened, or whether it was reported to police.
\end{abstract}

Second, questions were structured in a behaviorally specific manner to ensure precise communication of the types of events and circumstances being assessed, thereby increasing the likelihood that interpersonal victimization would accurately be detected through self-report (see Koss, 1993). Below is an example of the behaviorally specific questions used to assess for sexual assault:

Has a man or boy ever put a sexual part of his body inside your private sexual parts, inside your rear end or inside your mouth when you didn't want them to?

(Not counting any incidents you already told me about) has anyone, male or female, ever put fingers or objects inside your private sexual parts or inside your rear end when you didn't want them to?

(Not counting any incidents you already told me about) has anyone, male or female, ever put their mouth on your private sexual parts when you didn't want them to?
(Not counting any incidents you already told me about) has anyone ever made you touch their private sexual parts when you didn't want them to?

and, for boys only,

(Not counting any incidents you already told me about), has a woman or girl ever put your sexual private part in her mouth or inside her body when you didn't want her to?

Telling someone about CSA. Adolescents who reported that they had experienced CSA in response to the behaviorally specific screening questions were asked whether or not they had ever told anyone about the incident(s). For purposes of this study, this is defined as the adolescent's having disclosed to someone (i.e., adult or peer) about the first incident that occurred. A separate question was asked to determine if the adolescent was aware of whether a formal report was made to the police, child protection, or other authorities. The focus of this study was on whether the adolescent ever told anyone about the assault, rather than whether a formal report to authorities was made.

\section{CSA Incident Characteristics}

Penetration assault. Adolescents reporting a CSA experience were asked whether the assault involved penetration (i.e., anal, oral, digital, or vaginal).

Relationship to the perpetrator. Adolescents were asked to identify the perpetrator of the sexual assault. Responses were collapsed into four separate categories: father/stepfather, other relative (e.g., uncle, grandparent), unrelated acquaintance, and stranger. Adolescents were also asked two specific questions to assess the degree of the relationship: "Had you ever seen (any of) the person(s) who did this to you before?" and "Did you know the person(s) fairly well or not?" Adolescents who responded affirmatively to both questions were considered to have a close relationship to the offender.

Degree of life threat. A single question was used to determine whether adolescent participants feared that their life might be at stake during the assault: "During this (these) incidents were you ever afraid that you might be killed?"

Physical injury. All adolescents reporting CSA were asked, "Did you suffer serious physical injuries, minor injuries, or no injuries, as a result of the incident?" Physical injury was coded as the adolescent's having reported either minor or serious injuries.

Victim substance use. Participants were also asked whether they had been using substances at the time of the assault (i.e., "Were you using drugs or alcohol at 
the time of the incident?"). Responses included (a) drugs (b) alcohol (c) both (d) neither. This item was recoded to indicate whether subjects reported any substance use (alcohol, drugs, or both) at the time of the assault.

\section{RESULTS}

Analyses are presented in three separate stages. First, general demographic data and descriptive data for the sexual assault incident characteristic variables are presented. Next, results of chi-square analyses are presented that examined differences in rates of assault disclosure across the incident characteristics. Last, a series of hierarchical logistic regression analyses are presented to examine whether there are different correlates of CSA disclosure as a function of race or gender.

Within this nationally representative sample of adolescents, $326(8.1 \%)$ reported having experienced an event that met criteria for CSA. Of the 326 adolescents who experienced CSA, 71 were boys $(21.9 \%)$ and 254 $(78.1 \%)$ were girls. With regard to race, over half of adolescents who indicated that they had experienced CSA were European American (58.2\%), one quarter were African American (23.6\%), and an even smaller number were Hispanic $(9.4 \%)$ or from other ethnic backgrounds $(8.2 \%)$.

\section{Characteristics of the Assault}

With respect to assault characteristics, nearly one third of the 326 sexual assaults $(n=100 ; 30.7 \%)$ involved penetration, thus meeting the legal definition for rape. About one quarter (26.8\%) of these 326 adolescents indicated that they had feared for their life during the incident. Approximately $10 \%$ of adolescents reported physical injury during the assault and $6.7 \%$ reported the use of alcohol or drugs. Nearly two thirds $(64.1 \%)$ of the assaults were single (as opposed to series) assaults. About three quarters of the adolescents were acquainted with the perpetrator $(76.4 \%)$. More specifically, $4.3 \%$ identified the perpetrator as their father or stepfather, $17.5 \%$ as another relative, and $52.8 \%$ as an unrelated acquaintance. Approximately one quarter of the adolescents indicated that the perpetrator was a stranger. Six adolescents $(1.8 \%)$ indicated that they knew the perpetrator but did not identify a specific relationship, and two did not answer the question.

\section{Telling Someone About the CSA}

Approximately two thirds (68.1\%) of CSA victims reported that they had told another person that they had experienced a sexual assault. Of these 222 chil- dren, $10(4.5 \%)$ indicated that the first person they told about the sexual assault was a police officer or social worker; approximately one third of adolescents reported that the first person they told was a close friend $(39.3 \%)$ and another third specified a mother or stepmother $(34.3 \%)$. The remaining adolescents indicated that they disclosed to another relative $(6.1 \%)$, teacher $(1.8 \%)$, father or stepfather $(1.7 \%)$, or doctor or other health professional (1.3\%). An additional $3.4 \%$ of adolescents indicated that they had disclosed to "someone else," whom they did not specify, and $3.9 \%$ refused or replied that they did not know to whom they had first told about their assault. When asked specifically about whether the incident had been reported to the police, child protection, or any other authority, only $75(33.6 \%)$ responded affirmatively.

As seen in Table 1, girls were more likely to have told someone than boys $(74.0 \%$ vs. $46.5 \%)$. Significant racial/ethnic differences were also found. Chisquare analyses revealed that European American adolescents were more likely to disclose than were African American adolescents, $\chi^{2}(1, N=266)=9.6$, $p<.01$, or adolescents who reported Other racial/ ethnic categories, $\chi^{2}(1, N=210)=5.0, p<.01$. However, rates of disclosure for European American adolescents did not differ from Hispanic adolescents, nor were significant differences found between Hispanic and African American adolescents.

Assault characteristics were also examined in relation to telling someone about the assault. As seen in Table 2, life threat was significantly associated with increased likelihood of telling another person about the assault. Rates of telling did not differ as a function of other incident characteristics (i.e., injury, victim substance use, single vs. series assault, or penetration assault). However, the relationship between the victim and offender was significantly related to the likelihood of disclosure. Adolescents assaulted by a relative were significantly more likely than those assaulted by a father $\chi^{2}(1,71)=7.0, p<.01$, stranger, $\chi^{2}(1,132)=$ $5.5, p<.05$ or nonrelative $\left(\chi^{2}(1,229)=2.9, p<.001\right)$ to tell someone about their sexual assault (see Table 2 ).

\section{Logistic Regression Analyses}

A series of logistic regression analyses was conducted to examine whether there were different correlates of CSA disclosure as a function of race or gender. In the first logistic regression analysis, demographic variables (age, gender, race) were entered on the first step, followed by interaction terms between gender and each of the incident characteristics (e.g., Gender $\times$ Life Threat; Gender $\times$ Physical Injury) to predict disclosure of sexual assault. The second logistic regres- 
TABLE 1: Rates of Telling Someone About First Child Sexual Abuse (CSA) as a Function of Demographics

\begin{tabular}{lrcc}
\hline & \multicolumn{3}{c}{ Disclosed CSA } \\
\cline { 2 - 4 } Variable & $\mathrm{N}$ & $\%$ & $\chi^{2}$ \\
\hline Gender & & & $19.34^{* *}$ \\
$\quad$ Boys & 33 & 46.5 & \\
$\quad$ Girls & 188 & 74.0 & \multirow{2}{*}{. } \\
Race & 142 & 75.1 & \\
$\quad$ Caucasian & 43 & 55.8 & \\
African American & 21 & 67.7 & \\
Hispanic & 15 & 55.6 & \\
Other & & & $n s$ \\
Age & 17 & 68.0 & \\
12 & 26 & 76.5 & \\
13 & 29 & 63.0 & \\
14 & 36 & 64.3 & \\
15 & 59 & 66.3 & \\
16 & 54 & 71.1 & \\
17 & & & \\
\hline
\end{tabular}

NOTE: $n s=$ not significant.

$* * p<.01$.

TABLE 2: Rates of Telling Someone About Child Sexual Abuse by Incident Characteristics

\begin{tabular}{|c|c|c|c|c|c|}
\hline \multirow[b]{3}{*}{ Incident Characteristic } & \multicolumn{4}{|c|}{ Disclosure } & \multirow[b]{3}{*}{$\chi^{2}$} \\
\hline & \multicolumn{2}{|c|}{ Yes } & \multicolumn{2}{|c|}{ No } & \\
\hline & $\mathrm{n}$ & $\%$ & $\mathrm{n}$ & $\%$ & \\
\hline Physical injury ( $n=34,10.4 \%)$ & 24 & 70.6 & 10 & 29.4 & ns \\
\hline $\begin{array}{l}\text { Victim used substances } \\
\quad(n=22,6.7 \%)\end{array}$ & 15 & 68.2 & 7 & 31.8 & ns \\
\hline $\begin{array}{l}\text { Single (vs. series) assault } \\
\qquad(n=209,64.1 \%)\end{array}$ & 142 & 67.9 & 67 & 32.1 & $n s$ \\
\hline Life threat $(n=88,26.9 \%)$ & 71 & 80.7 & 17 & 16.3 & $8.8^{* *}$ \\
\hline $\begin{array}{l}\text { Penetration assault ( } n=100 \text {, } \\
\text { 30.7) }\end{array}$ & 72 & 72.0 & 28 & 28.0 & $n s$ \\
\hline Identity of perpetrator & & & & & $13.9 * *$ \\
\hline Father $(n=14,4.4 \%)$ & 8 & 57.1 & 6 & 42.9 & \\
\hline Relative $(n=57,17.9 \%)$ & 50 & $87.7 *$ & 7 & 12.3 & \\
\hline $\begin{array}{l}\text { Unrelated acquaintance } \\
(n=172,52.9 \%)\end{array}$ & 107 & 62.2 & 65 & 37.8 & \\
\hline Stranger $(n=75,23.0 \%)$ & 53 & 70.7 & 22 & 29.3 & \\
\hline $\begin{array}{l}\text { Know perpetrator }(n=249 \text {, } \\
76.4 \%)\end{array}$ & 168 & 67.5 & 81 & 32.5 & ns \\
\hline
\end{tabular}

NOTE: $n s=$ not significant

$* p<.05 . * * p<.01$.

sion was a repeat of the first, with the exception that interaction terms contained race rather than gender. With respect to race/ethnicity, interactions were only examined for African American adolescents. The reasons for this were (a) specific a priori hypotheses were only made for African American adolescents, (b) there were few adolescents from the other racial/ethnic groups who disclosed sexual assault experiences
(Hispanic $n=21$; Other $n=15$ ), and (c) there were no significant differences between Hispanics and African Americans or between Hispanics and European Americans in rates of disclosure. Results of these logistic regression analyses indicated that there were significant interactions between gender and the incident characteristics and between race and the incident characteristics in the prediction of CSA disclosure. More specifically, Gender $\times$ Penetration (odds ratio $[\mathrm{OR}]=0.2, p<.05$ ), Gender $\times$ Knowing the Perpetrator $(\mathrm{OR}=0.2, p<.05)$, African American $\times$ Penetration Assault $(\mathrm{OR}=14.6, p<.01)$, and African American $\times$ Life Threat $(\mathrm{OR}=0.1, p<.05)$ were statistically significant. Because of these significant interactions in the prediction of CSA disclosure, separate hierarchical logistic regression models were examined for boys and girls and for African Americans and European Americans.

For each of the four models constructed, age, gender, and race (African American vs. White, Hispanic vs. White) were entered on the first step, and assault characteristics (life threat, single or series assault, physical injury, victim's use of substances during the assault, degree of acquaintanceship with perpetrator, penetration assault) were entered on the second step. As seen in Table 3, results of the first analysis (boys only) revealed that being African American was the only variable significantly associated with a lower likelihood of telling someone about the first CSA incident. The perception of life threat $(\mathrm{OR}=2.9, p<.01)$ significantly increased the likelihood of CSA disclosure for the girls (see Table 4). Being African American $(\mathrm{OR}=.30, p<.01)$, experiencing a physical injury $(\mathrm{OR}=.42, p<.05)$ and not knowing the offender $(\mathrm{OR}$ $=.41, p<.05)$ reduced the likelihood that female adolescents told someone about the assault. For European American adolescents, perception of life threat $(\mathrm{OR}=5.17, p<.01)$ and not experiencing physical injury $(\mathrm{OR}=0.3, p<.05)$ during the assault were significantly associated with telling (see Table 5). Finally, the hierarchical logistic regression model for African Americans indicated that being female $(\mathrm{OR}=7.7, p<$ $.05)$ and an assault involving penetration $(\mathrm{OR}=27.4$, $p<.05)$ significantly increased the odds of telling someone about the CSA (see Table 6).

\section{DISCUSSION}

The present study had two primary goals. First, this study examined correlates of CSA disclosure in a nationally representative sample of adolescents and determined whether correlates that have been identified in previous research could be replicated. Second, this research sought to determine whether there 
TABLE 3: Initial and Final Model Odds of Disclosure of Child Sexual Abuse for Male Adolescents $(n=64)$ as a Function of Demographic Variables and Assault Characteristics

\begin{tabular}{|c|c|c|c|c|c|c|}
\hline Step and Variable & $\beta$ & SE & Wald & $\begin{array}{l}\text { Step } \\
\text { OR }\end{array}$ & $\begin{array}{l}\text { Final } \\
\text { OR }\end{array}$ & $\begin{array}{c}95 \% \text { CI for } \\
\operatorname{EXP}(B)\end{array}$ \\
\hline \multicolumn{7}{|l|}{ Step 1: } \\
\hline \multicolumn{7}{|l|}{ Demographics } \\
\hline Age & 0.10 & 0.18 & 0.32 & 1.11 & 1.34 & $(0.88-2.04)$ \\
\hline African & & & & & & \\
\hline American & -1.77 & 0.72 & 5.97 & $0.17 *$ & $0.19 *$ & $(0.04-0.96)$ \\
\hline Hispanic & -0.78 & 0.81 & 0.94 & 0.46 & 0.68 & $(0.10-4.76)$ \\
\hline \multicolumn{7}{|l|}{$\begin{array}{l}\text { Step 2: Incident } \\
\text { characteristics }\end{array}$} \\
\hline Life threat & 1.25 & 0.89 & 1.96 & & 3.50 & $(0.61-20.20)$ \\
\hline $\begin{array}{l}\text { Physical } \\
\text { injury }\end{array}$ & 0.71 & 1.40 & 0.26 & & 1.40 & $(0.13-15.67)$ \\
\hline $\begin{array}{l}\text { Victim used } \\
\text { substances }\end{array}$ & 0.02 & 0.97 & 0.00 & & 1.78 & $(0.27-11.83)$ \\
\hline $\begin{array}{l}\text { Single vs. } \\
\text { series assault }\end{array}$ & -0.30 & 0.35 & 0.72 & & 0.60 & $(0.31-1.16)$ \\
\hline $\begin{array}{l}\text { Know } \\
\text { perpetrator }\end{array}$ & 0.62 & 0.69 & 0.82 & & 2.25 & $(0.60-8.38)$ \\
\hline $\begin{array}{l}\text { Penetration } \\
\text { assault }\end{array}$ & 1.68 & 0.63 & 7.04 & & 2.83 & $(0.76-10.64)$ \\
\hline
\end{tabular}

NOTE: $\mathrm{OR}=$ odds ratio

$* p<.05$.

TABLE 4: Initial and Final Model Odds of Disclosure of Child Sexual Abuse for Female Adolescents $(n=260)$ as a Function of Demographic Variables and Assault Characteristics

\begin{tabular}{|c|c|c|c|c|c|c|}
\hline Step and Variable & $\beta$ & SE & Wald & $\begin{array}{l}\text { Step } \\
\text { OR }\end{array}$ & $\begin{array}{c}\text { Final } \\
\text { OR }\end{array}$ & $\begin{array}{c}95 \% \text { CI for } \\
\operatorname{EXP}(B)\end{array}$ \\
\hline \multicolumn{7}{|l|}{ Step 1: } \\
\hline \multicolumn{7}{|l|}{ Demographics } \\
\hline Age & -0.03 & 0.10 & 0.11 & 0.97 & 0.98 & $(0.80-1.21)$ \\
\hline African & & & & & & \\
\hline American & -1.07 & 0.33 & 10.37 & $0.34 *$ & $* 0.30$ ** & $*(0.15-0.62)$ \\
\hline Hispanic & 0.28 & 0.49 & 0.32 & 1.32 & 0.90 & $(0.33-2.46)$ \\
\hline \multicolumn{7}{|l|}{$\begin{array}{l}\text { Step 2: Incident } \\
\text { characteristics }\end{array}$} \\
\hline Life Threat & 1.07 & 0.40 & 7.35 & & $2.93^{* *}$ & * $(1.35-6.37)$ \\
\hline $\begin{array}{l}\text { Physical } \\
\text { injury }\end{array}$ & -0.87 & 0.44 & 4.02 & & $0.42 *$ & $(0.18-0.98)$ \\
\hline $\begin{array}{l}\text { Victim used } \\
\text { substances }\end{array}$ & -0.02 & 0.73 & 0.00 & & 0.98 & $(0.24-4.13)$ \\
\hline $\begin{array}{l}\text { Single vs. } \\
\text { series assault }\end{array}$ & -0.23 & 0.17 & 1.89 & & 0.80 & $(0.57-1.10)$ \\
\hline $\begin{array}{l}\text { Know } \\
\text { perpetrator }\end{array}$ & -0.90 & 0.41 & 4.88 & & $0.41 *$ & $(0.18-0.90)$ \\
\hline $\begin{array}{l}\text { Penetration } \\
\text { assault }\end{array}$ & 0.57 & 0.37 & 2.38 & & 1.77 & $(0.86-3.66)$ \\
\hline
\end{tabular}

NOTE: $\mathrm{OR}=$ odds ratio

$* p<.05 . * * p<.01$.

might be differences in the rates and correlates of disclosure for boys and girls and for adolescents from different ethnic/racial backgrounds. First and foremost,
TABLE 5: Initial and Final Model Odds of Disclosure of Child Sexual Abuse for European American Adolescents $(n=$ 192) as a Function of Demographic Variables and Assault Characteristics

\begin{tabular}{|c|c|c|c|c|c|c|}
\hline Step and Variable & $\beta$ & $\mathrm{SE}$ & Wald & $\begin{array}{l}\text { Step } \\
\text { OR }\end{array}$ & $\begin{array}{c}\text { Final } \\
\text { OR }\end{array}$ & $\begin{array}{l}95 \% \text { CI for } \\
\text { Final OR }\end{array}$ \\
\hline \multicolumn{7}{|l|}{ Step 1: } \\
\hline Demographics & & & & & & \\
\hline Age & -0.05 & 0.12 & 0.17 & 0.95 & 1.00 & $(0.78-1.26)$ \\
\hline Gender & 0.68 & 0.40 & 2.94 & 2.37 & 2.29 & $(0.97-5.38)$ \\
\hline \multicolumn{7}{|l|}{$\begin{array}{l}\text { Step 2: Incident } \\
\text { characteristics }\end{array}$} \\
\hline Life threat & 1.64 & 0.57 & 8.29 & & $5.17 * *$ & $=(1.69-15.82)$ \\
\hline $\begin{array}{l}\text { Physical } \\
\text { injury }\end{array}$ & -1.15 & 0.56 & 4.18 & & $0.32 *$ & $(0.10-0.95)$ \\
\hline $\begin{array}{l}\text { Victim used } \\
\text { substances }\end{array}$ & 0.08 & 0.62 & 0.02 & & 1.08 & $(0.32-3.65)$ \\
\hline $\begin{array}{l}\text { Single vs. } \\
\text { series assault }\end{array}$ & -0.22 & 0.20 & 1.28 & & 0.80 & $(0.54-1.18)$ \\
\hline $\begin{array}{l}\text { Know } \\
\text { perpetrator }\end{array}$ & -0.35 & 0.45 & 0.63 & & 0.70 & $(0.29-1.68)$ \\
\hline $\begin{array}{l}\text { Penetration } \\
\text { assault }\end{array}$ & 0.14 & 0.38 & 0.15 & & 1.16 & $(0.55-2.42)$ \\
\hline
\end{tabular}

NOTE: $\mathrm{OR}=$ odds ratio

$* p<.05 . * * p<.01$.

TABLE 6: Initial and Final Model Odds of Disclosure of Child Sexual Abuse for African American Adolescents $(n=$ 67) as a Function of Demographic Variables and Assault Characteristics

\begin{tabular}{|c|c|c|c|c|c|c|}
\hline Step and Variable & $\beta$ & SE & Wald & $\begin{array}{l}\text { Step } \\
\text { OR }\end{array}$ & $\begin{array}{c}\text { Final } \\
\text { OR }\end{array}$ & $\begin{array}{l}95 \% \text { CI for } \\
\text { Final OR }\end{array}$ \\
\hline \multirow{2}{*}{\multicolumn{7}{|c|}{$\begin{array}{l}\text { Step 1: } \\
\text { Demographics }\end{array}$}} \\
\hline & & & & & & \\
\hline Age & 0.09 & 0.17 & 0.24 & 1.09 & 1.00 & $(0.67-1.50)$ \\
\hline Gender & 1.60 & 0.72 & 5.01 & $4.97 *$ & $7.74 *$ & $(1.43-41.91)$ \\
\hline \multicolumn{7}{|l|}{$\begin{array}{l}\text { Step 2: Incident } \\
\text { characteristics }\end{array}$} \\
\hline Life threat & 0.51 & 0.68 & 0.57 & & 1.67 & $(0.44-6.31)$ \\
\hline $\begin{array}{l}\text { Physical } \\
\text { injury }\end{array}$ & -0.62 & 0.99 & 0.40 & & 0.54 & $(0.08-3.72)$ \\
\hline $\begin{array}{l}\text { Victim used } \\
\text { substances }\end{array}$ & -5.84 & 22.27 & 0.07 & & 0.00 & $(0.00-0.03)$ \\
\hline $\begin{array}{l}\text { Single vs. } \\
\text { series assault }\end{array}$ & -0.39 & 0.35 & 1.28 & & 0.68 & (0.34-1.33) \\
\hline $\begin{array}{l}\text { Know } \\
\text { perpetrator }\end{array}$ & -0.92 & 0.71 & 1.68 & & 0.40 & $(0.10-1.60)$ \\
\hline $\begin{array}{l}\text { Penetration } \\
\text { assault }\end{array}$ & 3.31 & 1.36 & 5.88 & & $27.40 *$ & $(1.89-397.8)$ \\
\hline
\end{tabular}

NOTE: $\mathrm{OR}=$ odds ratio

$* p<.05$.

it is important to note that most adolescents in this sample stated that they had told someone about their alleged CSA incidents. This is different from the findings of a number of other studies (Arata, 1998; Lamb \& Edgar-Smith, 1994; Smith et al., 2000; Sorenson \& Snow, 1991). Given that previous research has indi- 
cated that older children are more likely to make purposeful disclosures than younger children (Nagel et al., 1997) and that the present sample consisted solely of adolescents, it is possible that the older age of participants may account for this difference. Previous studies may have found a relationship between age and telling because much younger children, whose verbal skills are less well developed than older children, were included in the sample (Nagel et al., 1997; Sorenson \& Snow, 1991). It seems possible that language development, rather than age, might be a more significant factor in determining whether or not a victim tells someone about their assault.

In addition, in retrospective studies, such as Smith et al. (2000), many of the women experienced rapes before sexual assault prevention programs were implemented in schools. As noted by Smith et al. (2000), these types of programs focus on teaching children the importance of telling, making it reasonable to assume that children today would be more likely to tell someone about a sexual assault than women who were raped before the widespread implementation of these programs.

It is also important to point out that the present study examined telling someone about a sexual assault experience in contrast to making an official report to legal authorities or child protective services. Telling a parent or friend about an assault does not ensure that the assault will be officially reported, and in fact, research has indicated that few children actually report their assaults to police or authorities. In the National Women's Study (Hanson, Resnick, Saunders, Kilpatrick \& Best, 1999), fewer than $10 \%$ of respondents indicated that their assault had been reported to the police or child protection. In the present study, the rate of reporting improved in that approximately one third $(33.6 \%)$ of the adolescents stated that their assault had been reported to the authorities. However, this still means that approximately two thirds of these sexual assaults were not reported to the appropriate authorities. In contrast, approximately two thirds $(68.1 \%)$ of the adolescent victims in the present study reported that they had told another person about their sexual assault. Thus, telling someone does not necessarily mean the assault will be reported to authorities, which highlights the importance of differentiating between a disclosure and an official report.

A number of important findings emerged from this study with regard to the specific research questions. Consistent with hypotheses, one indicator of assault severity, the perception of life threat, was related to an increased likelihood of disclosure. However, in analyses involving the entire sample, three other severity indices, degree of physical injury expe- rienced, penetration, and whether the assault was a single or series incident, were unrelated to telling. Interestingly, when separate models were examined, penetration and physical injury were associated with disclosure. Specifically, for the African American adolescents, penetration was a significant correlate of disclosure $(\mathrm{OR}=27.5)$. This emphasizes the importance of examining correlates as a function of race/ethnicity.

The findings for physical injury were somewhat counterintuitive, in that sustaining an injury during the assault reduced the likelihood of disclosure for the girls and for the European American adolescents. It is possible that physical injury was not related to disclosure because so few adolescents in the sample experienced physical injury (10.4\%) (either minor or severe) during the CSA incident. It may also be the case that those who were injured were also more likely to have been threatened by the perpetrator, specifically regarding prohibitions against disclosure. In support of this hypothesis, $60 \%$ of adolescents who were physically injured also reported life threat. Although the specific content of the threats was not examined, this does offer a possible explanation for why physical injury actually reduced the likelihood of disclosure. It is also important to state that previous research has yielded equivocal findings regarding relationships between assault severity and disclosure (Paine \& Hansen, 2002). Some studies reported that victims of abuse at either extreme (i.e., intercourse or noncontact forms of abuse) were least likely to disclose (e.g., Gomes-Schwartz, Horowitz, \& Cardarelli, 1990; Sauzier, 1989), whereas other studies have indicated that victims of more severe abuse (i.e., contact sexual abuse) were less likely to disclose (Arata, 1998). Clearly, relationships among assault severity and disclosure require further examination.

Also consistent with hypotheses and with the research literature (e.g., Paine \& Hansen, 2002; Widom \& Morris, 1997), gender of the adolescent was related to telling someone, such that girls were significantly more likely to tell someone than were their male counterparts. Although there could be several explanations for this finding, it seems likely that a number of factors contribute to making boys less likely to tell someone about their CSA experiences. For example, this includes fear of being viewed as homosexual (if the offender were male) or male socialization practices, which convey a number of messages, including that boys are powerful, invulnerable human beings and that a boy/man should always welcome sexual activity, in whatever form, from a female (Faller, 1989).

Analyses also revealed that, as predicted, race/ethnicity was related to telling someone, such that Afri- 
can American adolescents were less likely to tell than were European American adolescents. It seems possible that African Americans are less likely to tell someone due to the fear of being disbelieved. Previous research with adult African American women has suggested that this population may be less likely to report to authorities due to an expected lack of societal support (Wyatt, 1992). Although this has not been investigated with African American boys/men, the same may hold true for this racial/ethnic subgroup.

Although it was reasonable to assume that the use of substances might increase a victim's feeling of selfblame and thus reduce the likelihood of disclosure, this relationship was not found in the present study. It is important to note that very few adolescents even reported substance use during the assault (6.7\%), which could account for the absence of this relationship. In addition, studies in the adult literature typically ask whether the victim had been intoxicated. It seems possible that degree of substance use might factor into a person's decision to tell someone about their CSA experiences. If a person has had one drink, versus many drinks, it might make it easier to believe that they are less likely to be blamed by others. Because the current study did not assess whether the victim was intoxicated, this might explain the lack of a relationship between substance use and telling someone. It would be important for future studies to determine whether degree of substance use is related to telling someone about CSA experiences.

A closer relationship with the perpetrator and loyalty to that person has been consistently associated with a reduced likelihood of telling someone about CSA (Sauzier, 1989; Smith et al., 2000; Wyatt \& Newcomb, 1990). Somewhat in contrast with existing research, findings from this study indicated that victims assaulted by a relative were the most likely to disclose. Because this is an adolescent sample, one possibility is that adolescents may have a greater number of resources, less dependence on the perpetrator, and a more developed sense of identity, making them more likely to risk the consequences of telling than a younger child. However, it is important to note that victims assaulted by their fathers were less likely to disclose than those assaulted by a relative, which partially supports previous research. In other words, the closest of the offender-victim relationships, that is, father-child, did reduce the likelihood of disclosure.

A comparison of the models for African American and European American adolescents revealed two important differences. First, gender was a significant correlate of disclosure for African Americans but not for European Americans. That is, African American females were seven times more likely to tell someone than were their male counterparts, but no significant gender differences were found for European Americans. This suggests that there may be something in particular about being an African American male that inhibits these youths from telling someone about their CSA. Second, although severity of the assault was important for both groups, penetration assault was strongly related to telling someone for African Americans, whereas degree of life threat was related to telling for European Americans. The reasons for this finding are unclear and deserve further empirical attention. In addition, as observed for the female adolescents, physical injury reduced the likelihood of disclosure, and, as discussed earlier, it is possible that physical injury may be associated with increased fear.

Although the above findings should be replicated by subsequent research, they do indicate differences in the correlates of disclosure according to ethnicity and gender. These results also suggest that it may be particularly important to assess for sexual assault in African American children and boys, as these two groups appear less likely to disclose.

The study does have several specific limitations that need to be addressed. First, interviews were conducted by telephone. Although every effort was made to insure that adolescents could respond openly, it is possible that some participants may still have had some concerns about privacy and that others could overhear their conversations. Another limitation of a phone survey is that adolescents living in households without telephones were excluded. However, previous research has demonstrated that telephone methodology excludes only a very small number of participants. According to the 1990 U.S. Census, only $5 \%$ of U.S. households did not have telephones at any one point in time.

A third limitation centers on the fact that this was a retrospective study, meaning that adolescents were asked to recall past CSA and disclosure experiences, which may have produced biased responding, a limitation inherent in any retrospective design. On a related note, it is also possible that some adolescents may have fabricated their reports of sexual assault, but this seems unlikely given the number of questions asked about the reported sexual assault incidents. A final limitation is the lack of reliability or validity data available on the measures used to assess the sexual assault variables. The best available measure of reliability is the fact that these questions have been utilized in several national studies with consistently reliable results. Our prevalence rates for sexual assault are comparable to other large-scale national studies, providing support for the reliability and validity of these measures. In addition, as stated previously, pro- 
cedures were implemented to improve specificity of the measures. First, an introductory paragraph was presented to participants to orient them toward the sexual assault questions being assessed. Second, behaviorally specific questions were used to ensure precise communication of the types of events and circumstances being assessed, thereby increasing the likelihood that interpersonal victimization would accurately be detected through self-report (see Koss, 1993).

In conclusion, findings from this nationally representative sample of adolescents contribute to available knowledge regarding the relationships between sexual assault characteristics and disclosure. This study provides initial data to suggest that correlates of CSA disclosure differ for girls and boys and for adolescents of different racial/ethnic backgrounds. It will be important for future research to replicate these findings. Additionally, it will be important for future studies to examine correlates of CSA disclosure among other ethnic/racial groups (e.g., Asians, Hispanics, and Native Americans). An increased understanding of the correlates of CSA disclosure can have important implications for early intervention and prevention of revictimization.

\section{REFERENCES}

Arata, C. M. (1998). To tell or not to tell: Current functioning of child sexual abuse survivors who disclosed their victimization. Child Maltreatment, 3, 63-71.

Beitchman, J. H., Zucker, K. J., Hood, J. E., daCosta, G. A., Akman, D., \& Cassavia, E. (1992). A review of the long-term effects of child sexual abuse. Child Abuse and Neglect, 16, 101-118.

Bolton, F. G., Morris, L. A., \& MacEachron, A. E. (1989). Males at risk: The other side of child sexual abuse. Newbury Park, CA: Sage.

Bybee, D., \& Mowbray, C. T. (1993). An analysis of allegations of sexual abuse in a multi-victim day-care center case. Child Abuse and Neglect, 17, 767-783.

DiPietro, E. K., Runyan, D. K., \& Fredrickson, D. D. (1997). Predictors of disclosure during medical evaluation for suspected sexual abuse. Journal of Child Sexual Abuse, 6(1), 133-142.

Elliot, D. M., \& Briere, J. (1994). Forensic sexual abuse evaluations of older children: Disclosures and symptomatology. Behavioral Sciences and the Law, 12, 261-277.

Faller, K. C. (1989). Characteristics of a clinical sample of sexually abused children: How boy and girl victims differ. Child Abuse and Neglect, 13, 281-291.

Finkelhor, D. (1994). Current information on the scope and nature of child sexual abuse. The Future of Children, 4, 31-53.

Finkelhor, D., Hotaling, G., Lewis, I. A., \& Smith, C. (1990). Sexual abuse in a national survey of adult men and women: Prevalence, characteristics, and risk factors. Child Abuse and Neglect, 14, 19-28.

Fleming, J., Mullen, P. E., Sibthorpe, B., \& Bammer, G. (1999). The long-term impact of childhood sexual abuse in Australian women. Child Abuse and Neglect, 23, 145-159.

Friedrich, W. N. (1998). Behavioral manifestations of child sexual abuse. Child Abuse and Neglect, 22, 523-531.

Gomes-Schwartz, B., Horowitz, J. M., \& Cardarelli, A. P. (1990). Child sexual abuse: The initial effects. Newbury Park, CA: Sage.

Goodchilds, J. D., \& Zellman, G. L. (1984). Sexual signaling and sexual aggression in adolescent relationships. In N. M.
Malamuth \& E. Donnerstein (Eds.), Pornography and sexual aggression (pp. 233-243). Orlando, FL: Academic Press.

Hanson, R. F., Resnick, H. S., Saunders, B. E., Kilpatrick, D. G., \& Best, C. (1999). Factors related to the reporting of childhood rape. Child Abuse and Neglect, 23(6), 559-569.

Hecht, D. A., \& Hansen, D. J. (1999). Adolescent victims and intergenerational issues in sexual abuse. In V. B. Van Hasselt \& M. Hersen (Eds.), Handbook of psychological approaches with violent criminal offenders: Contemporary strategies and issues (pp. 303-238). New York: Plenum.

Holmes, W. C., \& Slap, G. B. (1998). Sexual abuse of boys: Definition, prevalence, correlates, sequelae, and management. Journal of the American Medical Association, 280(21), 1855-1862.

Kilpatrick, D. G., Acierno, R., Saunders, B., Resnick, H. S., Best, C. L., \& Schnurr, P. P. (2000). Risk factors for adolescent substance abuse and dependence: Data from a national sample. Journal of Consulting and Clinical Psychology, 68, 19-30.

Koss, M. P. (1993). Detecting the scope of rape: A review of prevalence research methods. Journal of Interpersonal Violence, 8, 198222.

Lamb, S., \& Edgar-Smith, S. (1994). Aspects of disclosure: Mediators of outcome of childhood sexual abuse. Journal of Interpersonal Violence, 9, 307-326.

Lipovsky, J. A., \& Kilpatrick, D. G. (1992). The child sexual abuse victim as an adult. In W. O. Donahue \&J. H. Geer (Eds.), The sexual abuse of children: Clinical issues (Vol. II, pp. 430-476). Hillsdale, NJ: Lawrence Erlbaum.

McNair, L. D., \& Neville, H. A. (1996). African American women survivors of sexual assault: The intersection of race and class. Women and Therapy, 18, 107-118.

Mey, B. J. V. (1988). The sexual victimization of male children: A review of previous research. Child Abuse and Neglect, 12, 61-72.

Nagel, D. E., Putnam, F. W., Noll, J. G., \& Trickett, P. K. (1997). Disclosure patterns of sexual abuse and psychological functioning at a 1-year follow-up. Child Abuse and Neglect, 21, 137-147.

Paine, M. L., \& Hansen, D. J. (2002). Factors influencing children to self-disclose sexual abuse. Clinical Psychology Review, 22, 271295.

Polusny, M. A., \& Follette, V. M. (1995). Long-term correlates of child sexual abuse: Theory and review of the empirical literature. Applied EO Preventive Psychology, 4(3), 143-166.

Richardson, D. \& Campbell, J. L. (1982). The effect of alcohol on attributions of blame for rape. Personality and Social Psychology Bulletin, 8, 468-476.

Roesler, T. A. (1994). Reactions to disclosure of childhood sexual abuse: The effect on adult symptoms. Journal of Nervous and Mental Disease, 182, 618-624.

Roesler, T. A., \& Wind, T. W. (1994). Telling the secret: Adult women describe their disclosures of incest. Journal of Interpersonal Violence, 9, 327-338.

Saunders, B. E., Kilpatrick, D. G., Hanson, R. F., Resnick, H. S., \& Walker, M. E. (1999). Prevalence, case characteristics, and longterm psychological correlates of child rape among women: A national study. Child Maltreatment, 4(3), 187-200.

Sauzier, M. (1989). Disclosure of child sexual abuse: For better or for worse. Psychiatric Clinics of North America, 12, 455-469.

Smith, D. W., Letourneau, E. J., Saunders, B. E., Kilpatrick, D. G., Resnick, H. S., \& Best, C. L. (2000). Delay in disclosure of childhood rape: Results from a national survey. Child Abuse Ev Neglect, 24, 273-287.

Sorenson, T., \& Snow, B. (1991). How children tell: The process of disclosure in child sexual abuse. Child Welfare, 70, 3-15.

Swenson, C. C., \& Hanson, R. F. (1998). Sexual abuse of children. In J. R. Lutzker, (Ed.), Handbook of child abuse research and treatment: Issues in clinical child psychology (pp. 475-499). New York: Plenum Press.

Watkins, B., \& Bentovim, A. (1992). The sexual abuse of male children and adolescents: A review of current research. Journal of Child Psychology and Psychiatry, 33, 197-248.

Widom, C. S., \& Morris, S. (1997). Accuracy of adult recollections of childhood victimization, Part 2: Childhood sexual abuse. Psychological Assessment, 9(1), 34-46. 
Wyatt, G. E. (1992). The sociocultural context of African American and White American women's rape. Journal of Social Issues, 48, 77-91.

Wyatt, G. E., \& Newcomb, M. (1990). Internal and external mediators of women's sexual abuse in childhood. Journal of Consulting and Clinical Psychology, 58, 758-767.

Rochelle F. Hanson, Ph.D., is an associate professor at the National Crime Victim's Research and Treatment Center at the Medical University of South Carolina (MUSC). She was a founding member and past president of the South Carolina Professional Society on the Abuse of Children. She currently serves on the board of directors for the American Professional Society on the Abuse of Children. She is on the editorial review board for several journals in the area of trauma and victimization. In addition to research, Dr. Hanson provides clinical supervision to psychology trainees and maintains a clinical practice.

Lisha Kievit, Ph.D., is in clinical practice in Charleston, SC. She received her Ph.D. in 1999 from the University of North Carolina at Greensboro. Dr. Kievit completed her predoctoral internship at the Medical University of South Carolina, where she received specialty training at the National Crime Victims Research and Treatment Center. She was subsequently employed by the College of Charleston, where she served as a staff psychologist and provided consultation and education in the area of violence against women. The focus of her clinical practice is women's issues.

Benjamin E. Saunders, Ph.D., is a professor in the Department of Psychiatry and Behavioral Sciences at the Medical University of South Carolina and director of the Family/Child Program of the National Crime Victims Research and Treatment Center. He is also on the faculty of MUSC's National Violence Against Women Prevention Research Center. Dr. Saunders serves on the editorial boards of several professional journals, and his work in the area of child abuse has been funded by several federal agencies. Dr. Saunders also maintains a clinical practice and often serves as an expert witness in legal cases.

Daniel W. Smith, Ph.D., is associate professor and director of training at the Medical University of South Carolina's National
Crime Victims Research and Treatment Center. His research interests revolve around variables that may mediate the relationship between child abuse and the range of outcomes associated with such abuse.

Dean G. Kilpatrick, Ph.D., is a professor of clinical psychology and director of the National Crime Victims Research and Treatment Center at the Medical University of South Carolina in Charleston. $\mathrm{He}$ is also director of MUSC's National Violence Against Women Prevention Research Center. His primary research interests include measuring the prevalence and mental health impact of rape, violent crimes, and other potentially traumatic events. He has published extensively and his research has been funded by a variety of federal agencies. He is the editor of the Journal of Traumatic Stress.

Heidi S. Resnick, Ph.D., is a professor of clinical psychology at the National Crime Victims Research and Treatment Center (NCVC), within the Department of Psychiatry and Behavioral Sciences at the Medical University of South Carolina. Dr. Resnick received her Ph.D. in clinical psychology from Indiana University-Bloomington in 1987. She completed her predoctoral internship at the West Los Angeles Veterans Administration Medical Center (VAMC), where she received clinical training and conducted research related to development of post-traumatic stress disorder in Vietnam combat veterans. This was followed by a postdoctoral fellowship at the $N C V C$, where Dr. Resnick was able to continue her research and clinical training with victims of crime. Dr. Resnick has published over 60 journal articles and book chapters related to etiology and treatment of post-traumatic stress disorder and other mental health outcomes following crime or other traumatic events. She has received funding for her research from the Centers for Disease Control and Prevention, NIMH, and the National Institute on Drug Abuse.

Kenneth J. Ruggiero, PhD., is an instructor at the Medical University of South Carolina's National Crime Victims Research and Treatment Center, where he recently completed an NIMH-supported postdoctoral fellowship. His research interests center on childhood victimization in relation to emotional and behavioral functioning, with particular emphasis on the identification of psychosocial interventions (and components of psychosocial interventions) that moderate these relations. 